\title{
MODELLING AND ANALYSIS ON IMPELLER OF CENTRIFUGAL COMPRESSOR
}

\author{
Dr. R. Rama Chandra ${ }^{1 *}$ (Professor), Dr. V. Naga Prasad Naidu ${ }^{2}$ (Professor), Lakshmi Priya Tiruchanur ${ }^{3}$ \\ (Student) \\ *1,2,3 Mechanical Department Intell Engineering College \\ *lprincipalskd@gmail.com, ${ }^{2}$ nagveluri@gmail.com, ${ }^{3}$ priya.lucky314@gmail.com
}

*Corresponding Author: -

Email: principalskd@gmail.com

\begin{abstract}
: -
Impeller is a main component of the Centrifugal Compressor where it has got a series of curved vanes, fitted inside shroud plates. Impeller is a rotating part of a centrifugal compressor, or other machine designed to move a fluid by rotation, which imparts Centrifugal force to the fluid and the fluid moves radially out. This presentation deals with the 3-D solid modeling, analysis and optimization on the impeller blades which are made of "LOW CARBON STEEL". The 3Dimensional Centrifugal compressor impeller model has been done using "CATIA V5" software. ANSYS is used for the analysis of this model. Von Mises stress and yield strength of the model are compared in order to observed whether the design is safe for the Carbon Steel material and also the displacements of the component in $X, Y$ and $Z$ directions.
\end{abstract}

Keywords: Impeller, Carbon steel, Von Mises stress

\section{(c) (\$) (i)}




\section{INTRODUCTION}

Centrifugal compressors are mainly used in the machinery devices which are used to raise pressure or induce the flow in the controlled volume. To the Centrifugal Compressor an impeller is a major component. In this Project, impeller is made of Low Carbon Steel where carbon percentage is $0.13 \%$ to $0.17 \%$, and the material used is SOLID 45 (with carbon content limited to $0.2-0.25 \%$ ), which is sufficient to obtain good mechanical characteristics and at the same time suitable for welding. Stainless steel overlay is provided on the casing internals for certain applications like CO2.This material has (also good for low temperature) having 2\% Chrome, 1\% Molybdenum and 0.13 to 0.17 Carbons. Given that the weld and surround zone are the same, a phenomenon of inter granular corrosion would appear to occur with higher carbon content. It is for this reason that there is a need to limit the carbon content. The inter-granular corrosion weakens the metallurgical bond between grains, which leads to the mechanical degeneration of the material.

\section{Functionality of impeller}

Impeller is a rotating component, which imparts a high kinetic energy to the fluid. The impeller may be single or double sided, but the fundamental theory is the same for both. Fluid is sucked into the impeller eye and whirled round at high speed by the vanes on the impeller disc. At any point in the flow of fluid through the impeller, a pressure head obtains the centripetal acceleration, so that the static pressure of the fluid increases from the eye to the tip of the impeller.

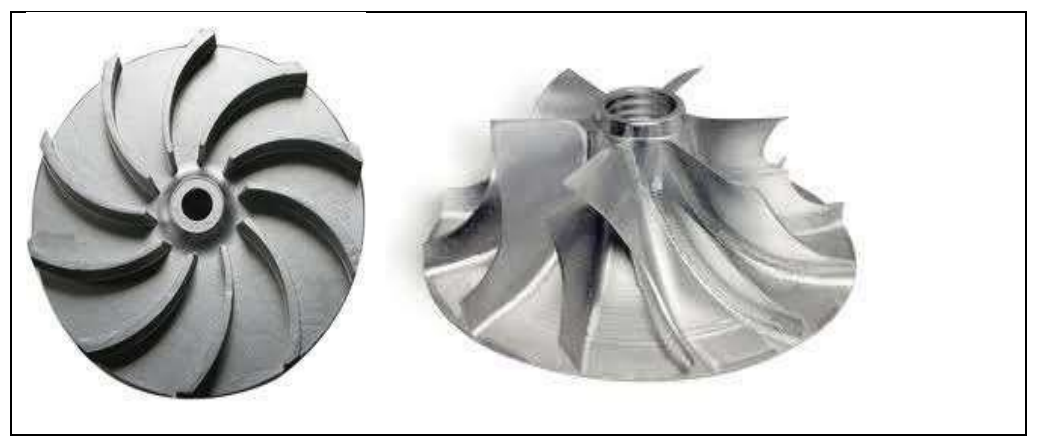

2D / $3 D$ impeller

The remainder of the static pressure rise is obtained in the diffuser, where the very high velocity of the fluid leaving the impeller tip is reduced to somewhere in the region of the velocity with which the fluid enters the impeller eye, it should be appreciated that friction in the diffuse will cause some loss in stagnation pressure. The normal practice is to design the compressor so that about half the pressure rise will occur in the impeller and in the diffuser.

\section{Methodology}

Normally, the impellers can be made of iron, Stainless steel, bronze etc. Usage of the Low Carbon Steel material to the impeller has its own advantages where it is the steel with a low carbon content has the same properties as iron, soft but easily formed and as the carbon content rises the metal becomes stronger and harder but less ductile. According to the American Iron and Steel Institute (AISI), steel is considered as carbon steel when

1. There is no minimum content chromium, cobalt, nickel, titanium and tungsten etc. to obtain desired alloying effect.

2. Specified minimum of copper is not more than $0.40 \%$.

3. Manganese $1.65 \%$, Silicon $0.60 \%$ and copper $0.60 \%$ should not be exceeded.
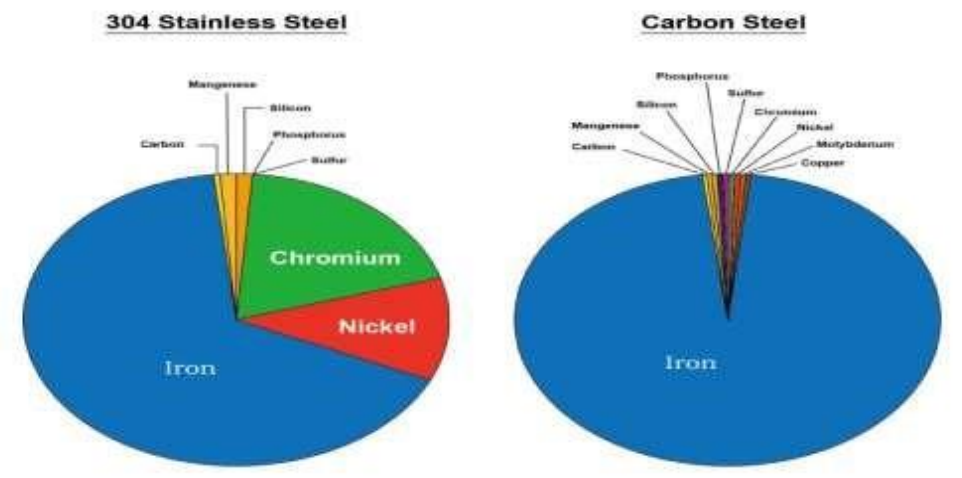

The sketch of the centrifugal compressor impeller as per specifications given by BHEL has drawn by using CATIA v5 software. 

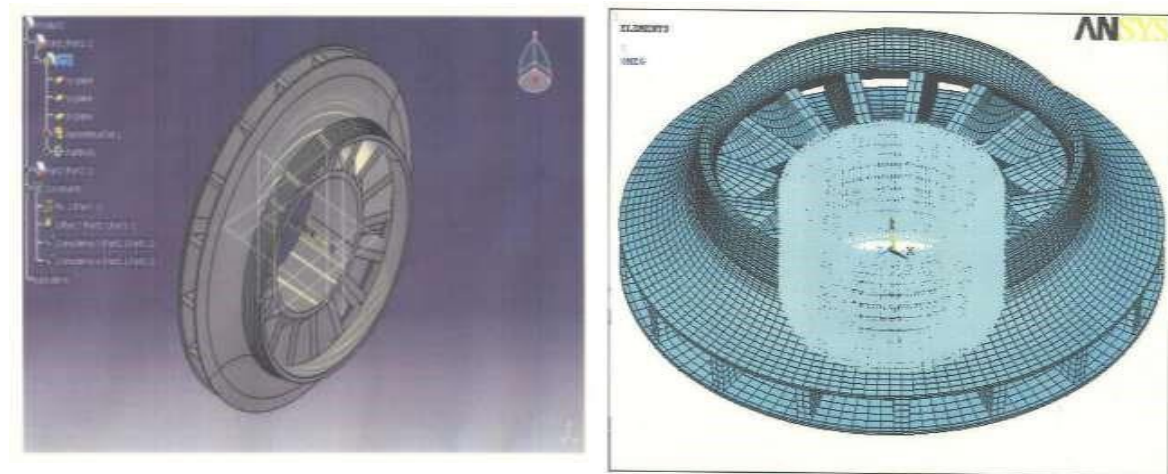

\section{Isometric view of impeller}

Boundary conditions applied at the Centre of the impeller.

The impeller disk is drawn in the sketcher of CATIA V5 software as shown in above Fig. and is brought to the part design and the part is revolved and saved as part. 1 file.

The shroud of the impeller is also drawn in the sketcher of CATIA V5 software as per the dimensions and is brought to the part design and is revolved and saved as part. 2 file.

From the half section of the assembly drawing vanes are drawn using pattern options with required thickness the required number of vanes are drawn.

The model of centrifugal compressor impeller has input into the ANSYS software and analysis is done.
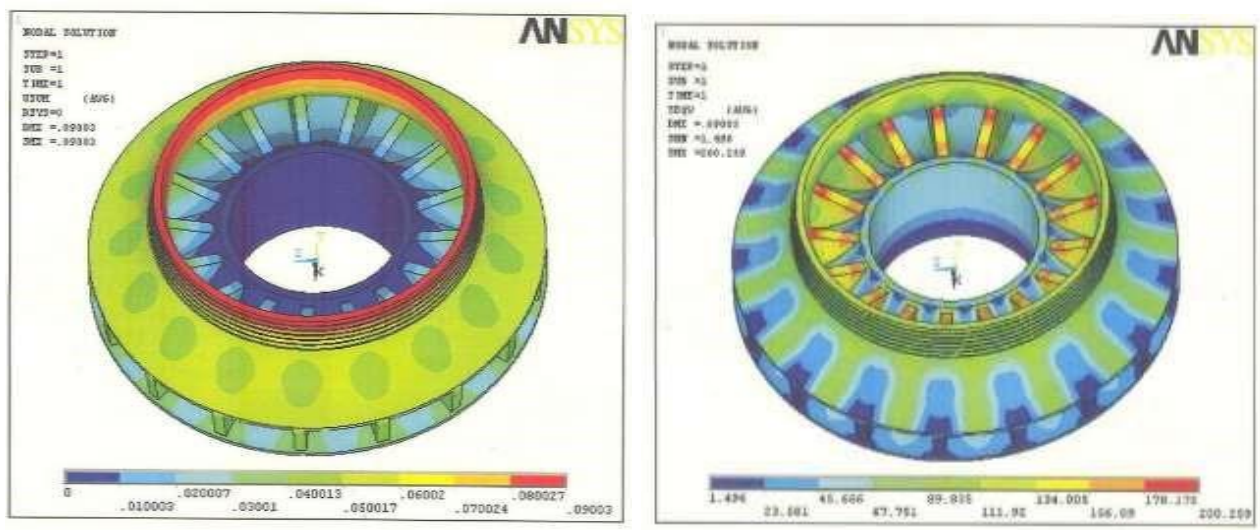

Figs: Displacement Vector Sum Von Mises Stress (Nodal Solution)

Variable Frequencies of Mode Shape:
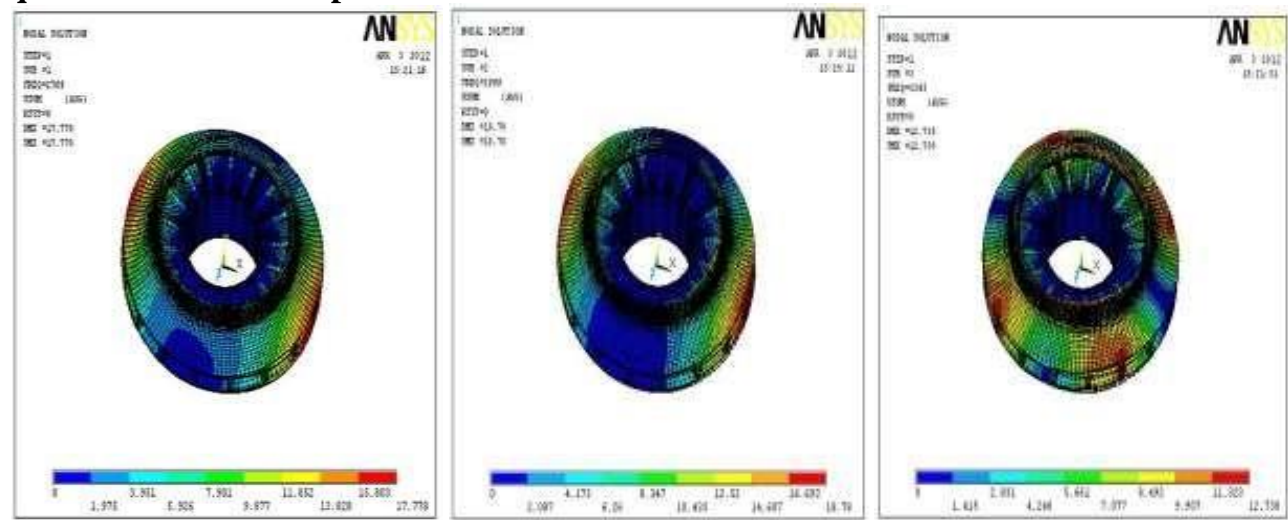

Fig: Mode shape 1 of impeller

Fig: Mode shape 2 of impeller

Fig: Mode shape 3 of impeller 


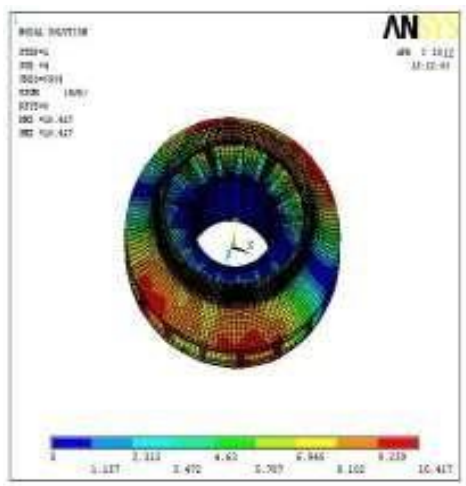

Fig: Mode shape 4 of impeller

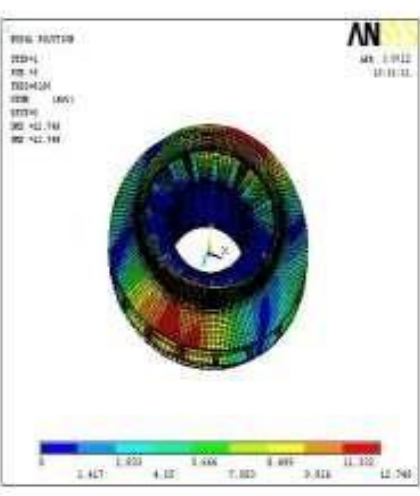

Fig: Mode shape 5 of impeller

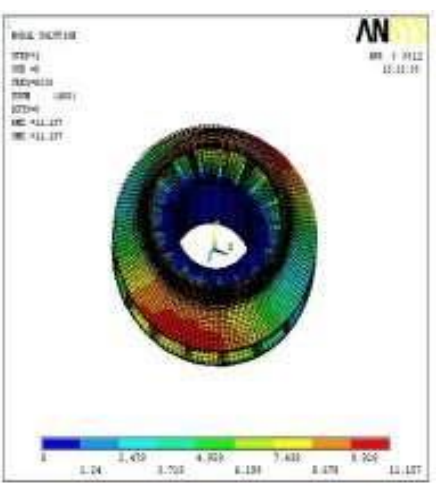

Fig: Mode shape 6 of impeller

The above Figures show the natural frequencies and different mode shapes are plotted in 6 different steps respectively. This is the analysis of the complete impeller taking the impeller disc, vanes and shroud. The element type SOLID 45 is given and analyzed. The impeller is constrained at the center in direction. Mapped mesh is employed. Angular velocity is applied and the MODAL analysis of the impeller is carried out. The results are obtained in post processor.

\section{Loading conditions:}

Mean critical speed (n): $7908 \mathrm{rpm}$

Operating speed $=110 \%$ of $7908=8698.8 \mathrm{rpm}$

Angular Velocity $=2 * 3.14 * \mathrm{n} / 60=2 * 3.14 * 8698.8 / 60$

\section{Data Required for Analysis:}

Mean critical speed (n):7908 rpm

Operating speed: $110 \%$ of mean critical speed

Number of vanes: 17

Material used: carbon steel

Density: $7.85 \mathrm{e}-9 \mathrm{~kg} / \mathrm{cubic} \mathrm{mm}$

Thickness of vanes: $12 \mathrm{~mm}$

Young's modulus: 2.1e5 Mpa

Poisson's ratio: 0.3

Yield strength: $350 \mathrm{Mpa}$

\section{Calculations:}

Operating speed $=110 \%$ of $7908=8698.8 \mathrm{rpm}$

Angular velocity $=2 * 3.14 * \mathrm{n} / 60=2 * 3.14 * 8698.8 / 60=910.4744 \mathrm{rad} / \mathrm{sec}$

\section{Results and discussions:}

\section{Analysis of centrifugal compressor impeller:}

Von Mises stress SEQV=200.259Mpa

Elemental Solution of von Mises stress=250.368 Mpa

Since the Von Mises stress obtained is below the yield strength value, $350 \mathrm{Mpa}$, so the design is safe for the material carbon steel used and also the displacements minimum and maximum values in $\mathrm{X}, \mathrm{Y}, \mathrm{Z}$ directions have been obtained.

\section{Modal analysis:}

Angular velocity is applied and the MODAL analysis of the impeller is carried out. The results are obtained in post processor.

\begin{tabular}{|l|l|l|l|l|}
\hline S NO & Frequency & $\begin{array}{l}\text { Load } \\
\text { Steps }\end{array}$ & Sub steps & Cumulative \\
\hline 1 & 2769 & 1 & 1 & 1 \\
\hline 2 & 2999 & 1 & 2 & 2 \\
\hline 3 & 5595 & 1 & 3 & 3 \\
\hline 4 & 5939 & 1 & 4 & 4 \\
\hline 5 & 6160 & 1 & 5 & 5 \\
\hline 6 & 6238 & 1 & 6 & 6 \\
\hline
\end{tabular}

The above table shows the natural frequencies and different mode shapes are plotted respectively.

\section{Conclusions}

The following are the important conclusions drawn from the present work. 
Static structural analysis post process results show that the von Mises stress acting on the centrifugal compressor impeller is $200.259 \mathrm{~N} / \mathrm{mm} 2$ with a maximum displacement of $0.09003 \mathrm{~mm}$.

The stresses developed on the impeller model are observed that, there magnitude is lower than its ultimate strength.

Dynamic analysis is carried out on the impeller model and mode shapes are developed. At the sixth mode the maximum frequency is $6238 \mathrm{~Hz}$.

\section{Reference}

[1].Rodgers, C., 2003, "High Specific Speed, High Inducer Tip Mach Number Centrifugal Compressor," ASME Paper No. GT2003-38949.

[2].Fisher, F. B., 1988, “Application of Map Width Enhancement Devices to Turbocharger Compressor Stages,” SAE Paper No. 880794.

[3].Cui, M., 2004, "Unsteady Flow Around Suction Elbow and Inlet Guide Vane in a Centrifugal Compressor," ASME Paper No. GT2004-53273.

[4].Schaber, U., 1997, "Non-Contact Vibration Measurements of Mistuned Coupled Blades,” ASME Paper No. 97-GT190.

[5].Sorokes, J. M., Borer, C. J., and Koch, J. M., 1998, "Investigation of the Circumferential Static Pressure NonUniformity Caused by a Centrifugal Compressor Discharge Volute," ASME Paper No. 98-GT-326.

[6].Filsinger, D., Sekavcnik, M., Ihli, T., Schulz, A., and Wittig, S., 2002, "Vibration Characteristics of a Radial Turbocharger Impeller," Proceedings of the 7th Int. Conference on Turbochargers and Turbocharging, London, pp. $117-127$.

[7].Hunziker R., Dickmann, H.-P., and Emmrich, R., 2001, "Numerical and Experimental Investigation of a Centrifugal Compressor With an Inducer Casing Bleed System," ATI-CST-025/01, Proceedings of 4th European Conference on Turbomachinery, Florence, Italy, pp. 319-329.

[8].Domercq, O., and Thomas, R., 1997, "Unsteady Flow Investigation in a Transonic Centrifugal Compressor Stage," AIAA J. 